\title{
ASSOCIATION ANALYSIS OF GENDER, JOB TYPE, EDUCATION LEVEL, INCOME LEVEL, RELIGION AND SPIRITUALITY LEVELS AGAINST THE TYPE OF THE SELECTED BANK COMMUNITY IN INDONESIA TAHUN 2015-2018
}

\author{
Adzan Noor Bakri \\ IAIN Palopo \\ $\bowtie$ adzan.noor@iainpalopo.ac.id
}

\begin{abstract}
: This study aims to analyze and explore the relationship of demographic aspects of society, including gender, education level, income level, occupation, religion, and spiritual level towards the types of banks that used by the people of Indonesia. The research method used is descriptive quantitative method with correspondence analysis technique. 200 communities have been chosen as a sample. They are the customers of conventional banks, sharia banks, or both of them. The results of this study argue that, not all demographic aspects of society have association or relationship with the type of bank selected by respondents. Only religion and spiritual level aspects have real associations. Muslim respondents are more likely to choose Islamic banks than nonmultifarious respondents. Respondents with high spiritual level tend to be associated with sharia banks rather than low ones. This research can be used for the marketing designer as one of the basic determines for the marketing strategy of the bank.
\end{abstract}

Keywords $\quad$ :gender, income, occupation, spirituallity.

\section{LATAR BELAKANG}

Isu perilaku nasabah bank syariah masih menjadi dikursus yang tetap hangat diperbincangkan. Memahami perilaku nasabah tidaklah mudah. Mereka (nasabah) terkadang harus terus terang menyatakan kebutuhan dan keinginannya. Namun sering juga mereka bertindak sebaliknya. Mereka juga mungkin tidak memahami motif dari setiap keputusan dan sikap mereka, sehingga sering kali terjadi perubahan pikiran secara mendadak pada detik-detik terakhir. Pola pikir dalam bertindak pun masih menjadi perdebatan yang hangat. Dikotomi antara nasabah rasional yang diklaim materialistis dengan nasabah emosional yang diklaim terpengaruh oleh faktor agama menjadi salah satu bagian yang menarik untuk ditemukan benang merahnya (Ajmi, Hussain, \& Al Saleh, 2009).

Motif adalah sesuatu yang sangat kompleks dalam perilaku pelanggan termasuk perilaku nasabah bank syariah. Persoalan bagaimana cara melakukan pemenuhan kebutuhan hidup selalu dihadapi oleh semua makhluk hidup dari zaman dahulu kala. Covey melalui buku The 8thHabit menyebutkan bahwa setidaknya manusia saat ini 
telah melalui lima zaman yaitu: zaman berburu, bertani, industri, pekerja, dan kebijaksanaan. Di setiap zaman ini manusia tetap dihadapkan dengan pemenuhan kebutuhan, namun perbedaan terletak pada cara memenuhi kebutuhan tersebut.

Manusia tergerak dan termotivasi memenuhi kebutuhannya tidak lebih didasari karena faktor materi. Ketika zaman bertani lebih menguntungkan dari berburu maka manusia akan pindah, lalu zaman berlalu manusia belajar banyak maka bertani pun berubah menjadi sektor industri. Kemudian dengan adanya industri maka lapangan pekerjaan terbuka dan menjadi pekerja dipilih secara masif oleh manusia. Manusia sepanjang dunia dan mereka masih ada di dunia ini akan selalu berhadapan dengan kebutuhan yang dalam ilmu ekonomi dibagi ke dalam tiga yaitu, primer, sekunder dan tersier. Pemenuhan kebutuhan selalu terkait dengan usaha atau pengorbanan. Dari usaha inilah dapat diketahui sikap dan perilaku manusia termasuk dalam memilih bank syariah. Kesimpulannya, manusia termotivasi berbuat karena ada kebutuhan yang ingin dipenuhi.

Kebutuhan sangat erat kaitannya dengan sasaran. Sasaran diartikan oleh Leon G. Schiffman, dan Leslie Lazar Kanuk ialah sebagai hasil yang diinginkan dari perilaku yang digerakkan oleh motivasi. Semua perilaku nasabah bank syariah berujung pada sasaran atau apa yang diinginkan oleh nasabah. Sasaran nasabah meliputi dua kategori yaitu: (1) sasaran umum yang bisa diartikan sebagai kategori-kategori umum. Seperti ketika nasabah menginginkan menabung di bank syariah karena ingin terbebas dari bunga bank. Alasan ini dikategorikan sebagai sasaran umum karena semua bank syariah tidak menggunakan sistem bunga seperti pada bank konvensional. (2) sasaran khusus, yaitu sasaran nasabah yang bersifat spesifik. Misalnya, ketika nasabah menginginkan produk bank syariah dengan akad tertentu. Menurut Schiffman, dan Kanuk, kebutuhan dan sasaran memiliki ketergantungan antara satu dengan yang lain. Menurut mereka tidak ada satu pun dari dia variabel ini yang bisa eksis tanpa yang lainnya (Balnkson, 2007).

Kebutuhan memanifestasikan motivasi yang menjadi daya penggerak. Sikap manusia ditentukan oleh jenis kebutuhan yang ingin dipenuhi. Bagaimana sikap nasabah ketika dihadapkan dengan satu produk bank syariah tertentu. Ketika produk itu akan dipilih, produk tersebut mampu memenuhi kebutuhannya. Ketika kebutuhannya berkisar pada kebutuhan materi, seperti keuntungan, kenyamanan, layanan maka nasabah akan memilih produk yang memenuhi kebutuhan tersebut. Di sinilah letak dinamika motivasi pada nasabah bank syariah.

\section{TEORI DAN METODE}

\subsection{Keputusan Memilih Jasa Bank Syariah}

Keputusan memilih bank Syariah mengacu pada teori yang dikemukakan oleh Philip Kotler tentag keputusan pembelian konsumen dan perilaku konsumen. Nasabah bank Syariah sebagai konsumen dipengaruhi oleh empat factor yaitu, (1) factor soial, (2) factor Budaya, (3) factor pribadi, dan (4) factor psikologis. teori ini terus berkembang sehingga mengerucut pada dimensi-dimensi atau karakter yang sifatnya statis dan 
dinamis dan melekat pada diri nasabah, seperti jenis kelamin, agama, tingkat Pendidikan, tingkat pendapatan bahkan tingkat spiritualitas. Pada dimensi ini nasabah bias dikelompokkna menjadi beberapa kategori yaitu: (nasabah muslim yang memilih bank Syariah, (2) nasabah non-muslim yang memilih bank Syariah, dan (3) nasabah non-muslim dan muslim yang tidak memilih bank Syariah.

Agama (religi) memang memiliki efek pada kesadaran hingga persepsi nasabah terhadap perbankan syariah. Sejauh ini, faktor agama adalah argumen paling klasik mengapa masyarakat memilih perbankan syariah dan argumen ini juga yang sangat menentukan persepsi mereka. Asumsi ini telah dibuktikan oleh beberapa penelitian seperti temuan dari Ahmad Haque pada nasabah bank di Malaysia (Haque, 2009). Penelitian di Jambi menemukan bahwa nasabah potensial yang akan berinteraksi atau memilih bank syariah berada di rentang usia di bawah 30 tahun dan di atas 55 tahun. Temuan ini juga mempertegas hasil studi di daerah Yogyakarta dan Jawa tengah yang menunjukkan bahwa semua jenis rumah tangga nasabah baik itu konsumsi atau produksi dan semua jenis produk yang dimanfaatkan baik itu tabungan ataupun pembiayaan rata-rata didominasi oleh nasabah yang berumur tua. Apa yang ditemukan di DIY dan Jawa Tengah juga terjadi di Jawa Timur. Jika disimpulkan, temuan studi ini memvalidkan apa yang telah diklaim oleh Bank Indonesia yang menyatakan bahwa nasabah berumur tua adalah kelompok nasabah yang dianggap potensial untuk berinteraksi dengan bank syariah (Bley dan Kuehn, 2004)

Tingkat pendidikan nasabah selama ini dianggap memiliki asosiasi terhadap persepsi dan sikap nasabah terhadap bank syariah. Asumsi ini telah dibuktikan pada studi kasus di Pakistan yang dilakukan oleh Khattak dan Rehman. Studi ini mendukung penelitian sebelumnya yang dilakukan oleh Amin di Borneo dan menunjukkan hasil yang sama. Temuan lain di Serawak Malaysia menemukan hal yang berbeda. Meski ditemukan pengaruh pada tingkat pendidikan dan kesadaran terhadap perbankan syariah, namun tingkat pendidikan tidak memiliki pengaruh yang signifikan terhadap persepsi nasabah bank syariah (Hamid dan Nordin, 2001). Hasil penelitian ini mendukung kesimpulan Haque, et al yang menemukan bahwa untuk nasabah di Malaysia, perbedaan antara tingkat pendidikan dengan persepsi dan keputusan nasabah terhadap perbankan syariah tidak terlalu signifikan (Haque, 2009).

Hasil temuan penelitian dari Bank Indonesia di Provinsi Jambi yang mengklaim bahwa masyarakat yang dianggap potensial akan berhubungan dengan bank syariah adalah mereka yang berpendidikan SD sampai dengan SMA. Hasil investigasi ini membuktikan klaim dari Bank Indonesia melalui penelitian mereka di wilayah DKI Jakarta dan sekitarnya bahwa masyarakat dengan tingkat pendidikan formal tinggi adalah masyarakat yang potensial berhubungan dengan bank syariah. Temuan di Sumatera Selatan juga menunjukkan hal yang relatif sama meski tingkat pendidikan nasabah yang dimaksud adalah tingkat pendidikan non-formal (Dusuki, 2008).

Berdasarkan temuan di Bangladesh oleh Khattak dan Rehman bahwa sebagian besar nasabah perbankan syariah berasal dari kalangan profesional, baik dari privat ataupun publik sektor (Khan, 2008). 
Kasus di Jambi menunjukkan bahwa nasabah potensial yang berinteraksi dengan bank syariah adalah nasabah yang memiliki karakter pekerja kasar dan setengah terampil. Hasil studi di DIY dan Jawa Tengah menunjukkan beberapa hal yang lebih spesifik yaitu: untuk masyarakat yang potensial akan memanfaatkan produk pembiayaan memiliki karakter pekerjaan di bidang pertanian, dan sektor pemerintahan (PNS) khusus untuk masyarakat dengan tipe rumah tangga konsumsi. Fenomena serupa juga ditemukan oleh tim peneliti Bank Indonesia di daerah Sumatera Utara. Studi di daerah ini menunjukkan bahwa variabel pekerjaan adalah salah satu faktor yang berpengaruh signifikan atau nyata terhadap keputusan masyarakat DIY dan Jawa tengah berinteraksi dengan bank syariah. Di daerah Sumatera Selatan, tim peneliti Bank Indonesia di daerah Sumatera Selatan menemukan bahwa masyarakat di daerah tersebut adalah masyarakat yang memiliki latar belakang pekerjaan sebagai pengusaha.

Pada kasus di Jambi menunjukkan bahwa nasabah potensial yang berinteraksi dengan bank syariah adalah nasabah yang memiliki karakter pekerja kasar dan setengah terampil. Temuan di atas lebih dekat dengan klaim Bank Indonesia pada hasil riset di DIY dan Jawa Tengah yang menemukan beberapa hal yang lebih spesifik yaitu: untuk masyarakat yang potensial akan memanfaatkan produk pembiayaan memiliki karakter pekerjaan di bidang pertanian, dan sektor pemerintahan (PNS) khusus untuk masyarakat dengan tipe rumah tangga konsumsi. Hal serupa juga ditemukan oleh tim peneliti Bank Indonesia di daerah Sumatera Utara. Investigasi di daerah ini menunjukkan bahwa variabel pekerjaan adalah salah satu faktor yang berdampak nyata terhadap keputusan masyarakat DIY dan Jawa tengah berinteraksi dengan bank syariah. Di daerah Sumatera Selatan, tim peneliti Bank Indonesia menemukan bahwa masyarakat di daerah tersebut adalah masyarakat yang memiliki latar belakang pekerjaan sebagai pengusaha.

Pada dimensi tingkat pendapatan, ada beberapa penelitian yang mengungkapkan adanya asosiasi antara variabel tingkat pendapatan responden dengan keputusan memilih bank syariah. Amin pada kasus Borneo dan temuan dari Khattak dan Rehman yang lebih spesifik menunjukkan bahwa nasabah perbankan syariah berada pada level middle income. Ada sebuah kesimpulan dari beberapa ahli yang telah membuktikan bahwa ada pengaruh positif antara tingkat pendapatan dengan keputusan nasabah memilih bank syariah. Bisa disimpulkan bahwa keputusan seseorang dalam perilaku ekonomi dipengaruhi oleh pendapatan mereka dan kemampuan mereka untuk menabung (ability to save), kemauan (willingness to save), dan kesempatan (opportunity to save). Pada tahun 2005 sebuah studi yang dilakukan oleh Sri Isnowati menyimpulkan bahwa pengaruh pendapatan per kapita terhadap tingkat tabungan sangat positif dan signifikan, baik jangka pendek maupun jangka panjang (Isnowati, 2005). Hasil penelitian ini bisa dianggap memperkuat salah satu prediksi bank Indonesia bahwa di daerah DIY dan Jawa Tengah yang menyatakan bahwa salah satu faktor yang mempengaruhi masyarakat untuk berinteraksi di bank syariah adalah variabel ekonomi pada aspek pendapatan. 
Ada sebuah argumentasi Kotler dalam salah satu bagian dari penjelasannya tentang aplikasi teori Marketing 3.0. Ia mengungkapkan bahwa manusia saat ini semakin humanis dan spiritual. Mereka mulai perlahan-lahan sadar akan daya sesuatu yang tersembunyi yang akan diperoleh dalam setiap perilakunya termasuk dalam konsumsi. Pelanggan saat ini banyak melirik perusahaan-perusahaan yang memiliki kepedulian sosial tinggi (Kotler et al., 2011). Argumentasi ini bukan tanpa alasan, Kotler melengkapinya dengan hasil penelitian terhadap pasar yang dianggap mapan seperti di Amerika dan Inggris. Spiritual merupakan inti dari komponen-komponen yang dimiliki manusia. Apa yang diungkapkan Covey sebenarnya sama dengan istilah spiritualitas dalam bahasa Arab yang dikenal dengan sebutan al-ruhiyyah atau alruhaniyyah. Kata ini juga digunakan untuk menyebut ruh, nyawa, nafas, wahyu, perintah dan rahmat. Istilah tersebut mengacu pada kata ruh yang secara bahasa berarti tiupan udara (al-rih). Hal ini senada dengan ungkapan al-Tirmīdzì yang mengartikan ruh sebagai sesuatu yang sangat halus (lathïf) seperti angin. Ia bersifat malakūt, berada di dalam darah dan daging manusia. Menurut Abu al-Abbas, ruh adalah esensi yang menyebabkan jasad menjadi hidup. Kata rūh mempunyai banyak arti. Selain kata rūh ada kata rīh yang berarti angin; dan kata rawh yang berarti rahmat.

Berdasarkan asumsi ini, ada dugaan ketika memilih menjadi nasabah bank syariah dengan konteks niat baik seperti ingin menabung untuk masa depan atau menyisihkan sebagian harta untuk amal (zakat, dan sedekah), hal tersebut dipengaruhi oleh kualitas spiritual yang baik. Demi membuktikan asumsi ini, pada studi ini dilakukan survei kepada 200 nasabah bank syariah untuk menguji seberapa besar pengaruh tingkat spiritualitas nasabah terhadap motivasi mereka memilih bank syariah. Hipotesis studi ini yaitu spiritualitas adalah motivasi baru yang hadir dalam keputusan nasabah memilih bank.

\subsection{Metode Penelitian}

Penelitian ini menggunakan jenis penelitian kuantitatif. Alasan menggunakannya adalah karena semua data dalam penelitian ini akan diolah dengan analisis statistik untuk membuktikan hipotesis. Semua data pada studi ini diambil dari dua sumber yaitu sumber primer dan sekunder. Data-data yang bersumber dari sumber primer diperoleh langsung di lapangan baik dari teknik survei. Untuk mengukur tingkat spiritual responden digunakan instrumen yang didasarkan pada teori dari Swinton. Ia membagi spiritualitas menjadi lima aspek yaitu; meaning, values, connecting, transcendence, dan becoming. Aemua data yang telah dikumpulkan dianalisis dengan teknik analisis deskriptif chi-square. Dalam melakukan analisis data, peneliti dibantu dengan perangkat lunak SPSS ver. 22. Ada dua dalil yang akan dijadikan dasar pada teknik analisis ini untuk membuktikan hipotesis.

a. Melihat nilai Asymp. Sig.

(1) Jika nilai Asymp. Sig < dari 0,05 maka terdapat hubungan yang signifikan antara kedua variabel. 
(2) Jika nilai Asymp. Sig > dari 0,05 maka tidak terdapat hubungan yang signifikan antara kedua variabel.

b. Melihat nilai Chi-Square

c. Jika nilai Chi-Square < dari 0,05 maka terdapat hubungan yang signifikan antara kedua variabel.

d. Jika nilai Chi-Square > dari 0,05 maka tidak terdapat hubungan yang signifikan antara kedua variabel.

\section{HASIL DAN PEMBAHASAN}

\subsection{Hasil Analisis Data}

Tabel 1 Karaktristik Responden

\begin{tabular}{|c|c|c|c|}
\hline Aspek. & Indikator & Frekuensi & $\%$ \\
\hline \multirow[t]{2}{*}{ Jenis Kelamin } & Laki-laki & 143 & 71,5 \\
\hline & Perempuan & 57 & 28,5 \\
\hline \multirow[t]{3}{*}{ Usia } & 26 s.d 35 tahun & 86 & 43 \\
\hline & $36 \mathrm{~s}, \mathrm{~d} 45$ tahun & 104 & 52 \\
\hline & $>45$ tahun & 10 & 5 \\
\hline \multirow[t]{4}{*}{ Pendidikan } & SMA sederajat & 18 & 9 \\
\hline & $\mathrm{S} 1$ & 162 & 81 \\
\hline & $\mathrm{S} 2$ & 17 & 8,5 \\
\hline & S3 & 3 & 1,5 \\
\hline \multirow[t]{4}{*}{ Pekerjaan } & PNS & 100 & 50 \\
\hline & Wirausaha & 40 & 20 \\
\hline & Karyawan Swasta & 43 & 21,5 \\
\hline & Sektor Pertanian & 17 & 8,5 \\
\hline \multirow[t]{4}{*}{ Pendapatan } & 500.000 s,d 999.999 & 4 & 2 \\
\hline & 1.000 .000 s.d 1.499 .999 & 73 & 36.5 \\
\hline & 1.500 .000 s.d 1.999 .999 & 84 & 32 \\
\hline & $>2.000 .000$ & 59 & 29,5 \\
\hline \multirow[t]{2}{*}{ Agama } & Islam & 171 & 85,5 \\
\hline & Non-islam & 29 & 14,5 \\
\hline \multirow[t]{4}{*}{ Jenis Bank } & Syariah & 76 & 38 \\
\hline & Syariah dan Konvensional & 70 & 35 \\
\hline & Konvensional & & \\
\hline & & 54 & 27 \\
\hline \multirow[t]{3}{*}{ Tingkat Spiritual } & Tinggi & 16 & 8 \\
\hline & Sedang & 162 & 81 \\
\hline & Rendah & 22 & 11 \\
\hline
\end{tabular}

Hasil tabulasi silang dan uji Chi-Square antara variabel agama dan jenis bank yang dipilih nasabah, responden kemudian dipecah menjadi tiga kelompok yaitu; (1) nasabah muslim yang hanya memilih bank syariah (n1 = 76), (2) nasabah muslim yang 
secara bersama-sama memilih bank syariah (n2 $=57$ ), dan konvensional, serta (3) nasabah non-muslim (n3 $=54)$.

Grafik 1. Hasil Tabulasi 3 Kelompok Responden (n1, n2, dan n3) berdasarkan Tingkat Pendidikan

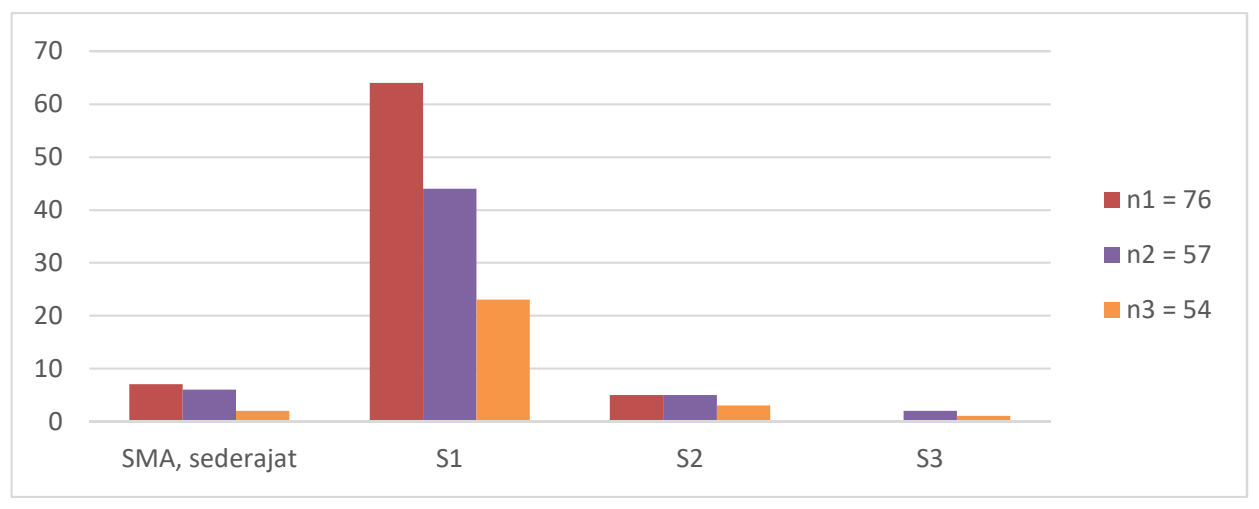

Semua responden dari ketiga kelompok didominasi oleh mereka yang memiliki pendidikan yang tinggi. Hasil yang ditunjukkan oleh analisis Chi-Square Tests menguatkan argumentasi bahwa tingkat pendidikan responden tidak memiliki asosiasi dengan jenis bank yang mereka pilih. Kesimpulan ini diperoleh setelah melihat nilai Asymp. Sig. 0,783 yang lebih besar dari 0,05. Kesimpulannya, tidak ditemukan perbedaan distribusi frekuensi yang signifikan antara responden yang memilih bank syariah, atau bank konvensional berdasarkan tingkat pendidikan. Tingkat pendidikan nasabah selama ini dianggap memiliki asosiasi terhadap persepsi dan sikap nasabah terhadap bank syariah.

Di investigasi ini, tidak ditemukan adanya asosiasi yang nyata antara lektor pekerjaan responden dengan jenis bank yang mereka pilih.

Grafik 2 Sektor Pekerjaan 3 Kelompok Responden (n1, n2, dan n3)

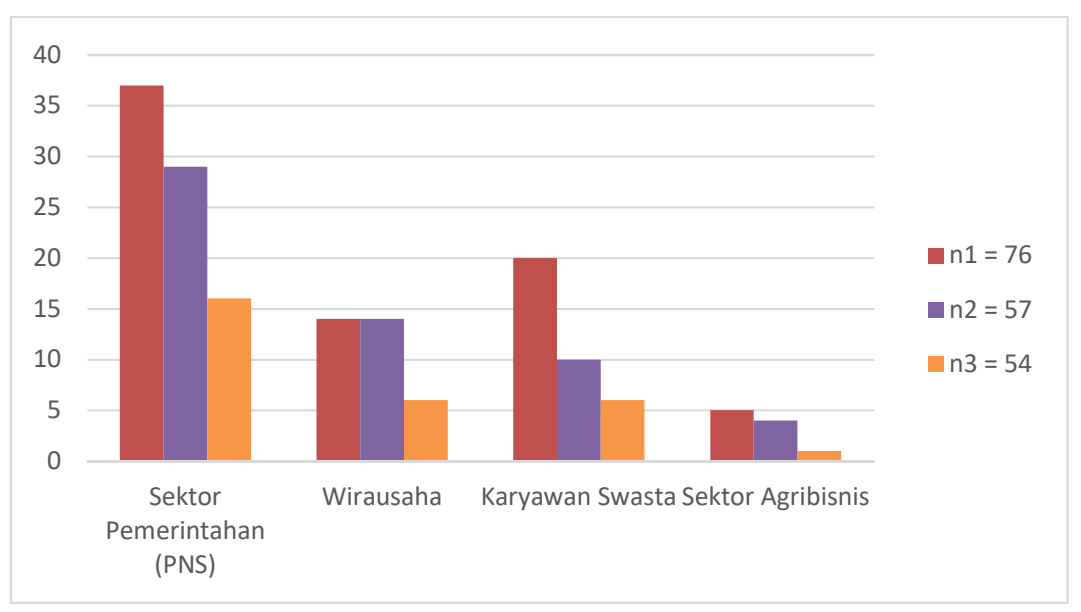

Hasil Chi-Square Tests antara setor pekerjaan dan jenis bank yang dipilih menunjukkan bahwa nilai Asymp. Sig, 0,331, yang lebih besar dari 0,05. Secara eksplisit ini berarti tidak ada asosiasi yang signifikan antara sektor pekerjaan responden dengan jenis bank yang mereka pilih. Tidak menjadi jaminan responden 
yang bekerja di sektor PNS cenderung memilih bank syariah dan yang bekerja di sektor wirausaha memilih memanfaatkan dua jenis bank atau hanya bank konvensional saja.

Latar belakang pekerjaan nasabah juga memiliki pengaruh terhadap persepsi nasabah.

Grafik 3 Tingkat Pendapatan 3 Kelompok Responden (n1, n2, dan n3)

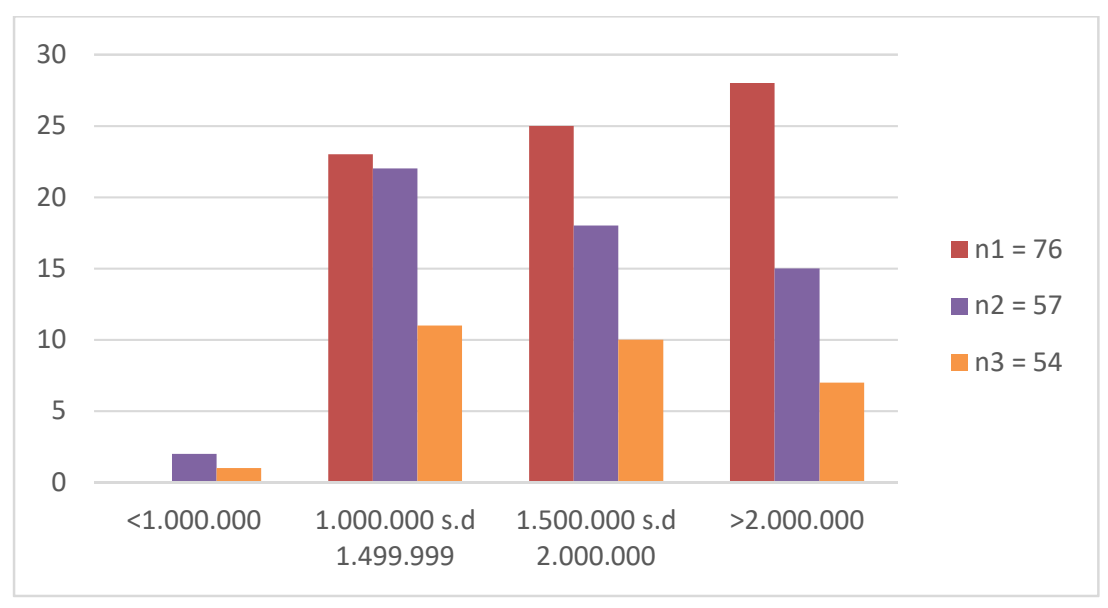

Jika dilihat dari hasil tabulasi pada grafik di atas, ada kenaikan frekuensi responden seiring dengan kenaikan pendapatan pada kelompok responden muslim yang hanya memilih bank syariah (n1), namun jika melihat kenaikan angka pada hasil tabulasi di atas, kenaikan tersebut tidak terlalu signifikan. Jika dipastikan dengan hasil Chi-Square Tests berdasarkan nilai Asymp. Sig. 0,340 yang lebih besar dari 0,05. Hasil ini menunjukkan bahwa tidak ada asosiasi yang signifikan antara tingkat pendapatan dan jenis bank yang dipilih responden. Temuan ini tidak mengoreksi beberapa temuan yang membuktikan bahwa tingkat pendapatan memiliki pengaruh signifikan terhadap keputusan berinteraksi dengan bank. Namun jika dilihat dari jenis bank yang dipilih responden sebenarnya tingkat pendapatan tidak menentukan secara nyata jenis bank yang dipilih.

Tingkat spiritual responden didapatkan setelah menghitung skor total dari jawaban mereka atas angket yang diberikan. Terdapat 3 kategori tingkat spiritual responden berdasarkan total skor jawaban tersebut seperti terlihat pada grafik berikut: 
Grafik 4 Deskripsi Tingkat Spiritual Responden (n=200)

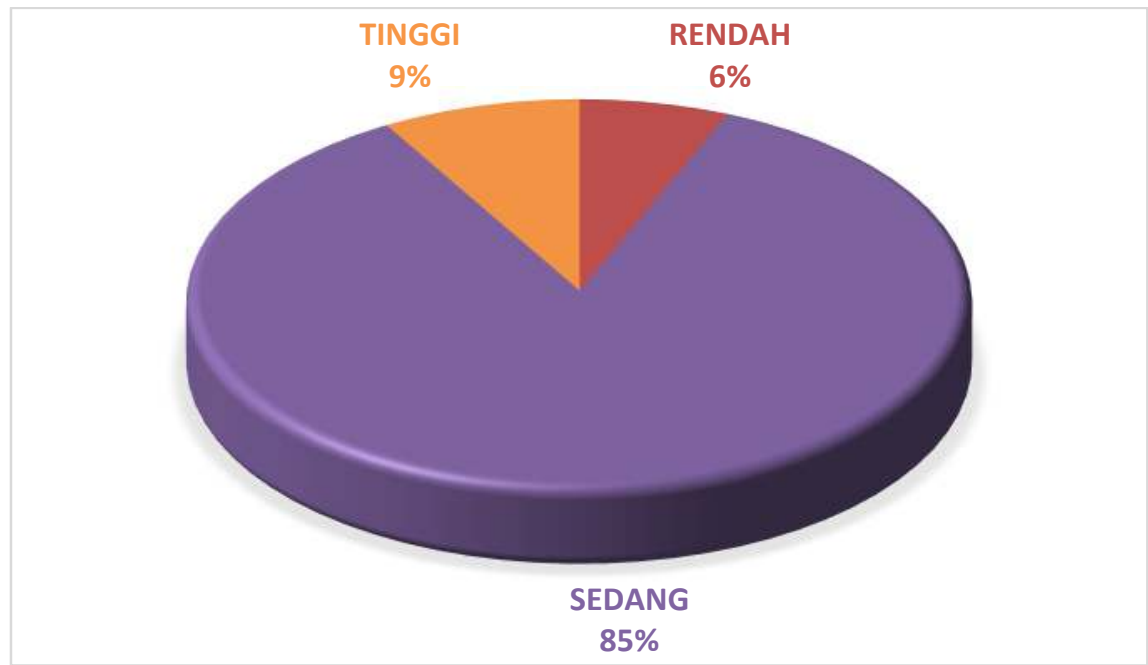

Hampir semua responden dalam studi ini memiliki tingkat spiritual yang cukup baik (sedang). Banyak diantara mereka melakukan berbagai cara untuk mendekatkan diri kepada Tuhan serta memperbaiki hubungan mereka dengan orang lain dan lingkungan. Hal ini wajar terjadi karena yang mengetahui kondisi dan kebutuhan kejiwaan manusia adalah manusia itu sendiri. Secara lebih terperinci, tingkat spiritual responden bisa dilihat beberapa aspek-aspek demografis, seperti jenis kelamin, usia, pendidikan, pendapatan, sektor pekerjaan, dan agama (Devlin dan Gerrard, 2005).

Grafik 5 Hasil Tabulasi Silang Spiritualitas Responden berdasarkan Jenis Bank yang Dipilih (n=200)

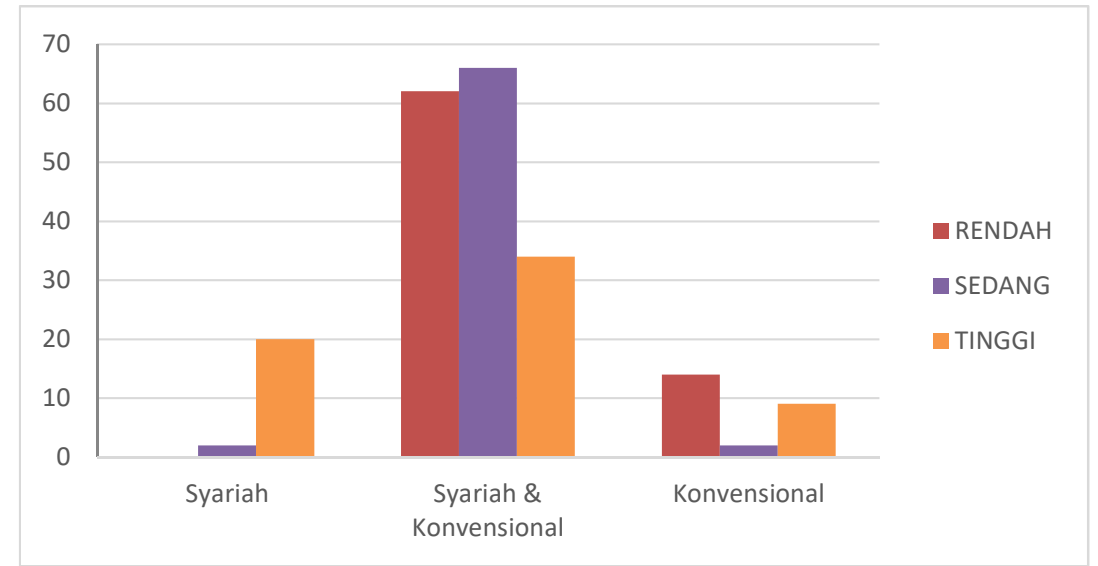

Sebuah fakta menarik ditunjukkan oleh hasil analisis pada grafik di atas. Ketika responden berada pada tingkat spiritualitas tinggi, mereka akan memilih bank syariah. Hal ini terlihat dengan adanya 14 orang responden dengan tingkat spiritual tinggi hanya memilih bank syariah, 66 responden dengan tingkat spiritual rendah memilih bank syariah dan konvensional, sedangkan 20 orang responden yang memilih bank konvensional berada pada tingkat spiritual yang rendah, dan tidak ada responden dengan tingkat spiritual tinggi memilih bank konvensional.

Data ini sebenarnya belum cukup kuat untuk langsung mengklaim bahwa ketika responden memiliki tingkat spiritual yang tinggi ia akan memutuskan untuk memilih 
bank syariah, oleh karena itu dibutuhkan Chi-Square Tests untuk mengetahui ada tidaknya asosiasi antara tingkat spiritual dengan jenis bank yang dipilih oleh responden. Berdasarkan hasil Chi-SquareTests diperoleh informasi yaitu: nilai Pearson Chi-Square $=66,508$, nilai ini lebih besar dari nilai Pearson Chi-Square yang ada pada tabel pada $\mathrm{df}=4$, dan nilai sig $=0,000$ yang lebih kecil dari 0,05 , dengan demikian dapat disimpulkan bahwa ada hubungan yang signifikan antara tingkat spiritual dengan jenis bank yang dipilih responden.

Uji compare means juga memperkuat temuan ini. Hasil uji One-way ANOVA diperoleh nilai sig pada tabel ANOVA $=0,000$ yang lebih kecil dari 0,05. Hasil ini membuktikan bahwa ada perbedaan yang nyata mengenai tingkat spiritual responden berdasarkan bank yang dipilih. Pada uji posthoctukey diperoleh temuan bahwa responden yang memilih bank syariah memiliki tingkat spiritual yang lebih tinggi daripada responden yang memilih bank konvensional.

Mempertegas temuan ini berikut disajikan deskripsi tingkat spiritualitas berdasarkan 3 kelompok responden (n1, n2, dan 3):

Grafik 6 Hasil Tabulasi Silang Tingkat Spiritual 3 Kategori Responden (n1, n2, dan n3)

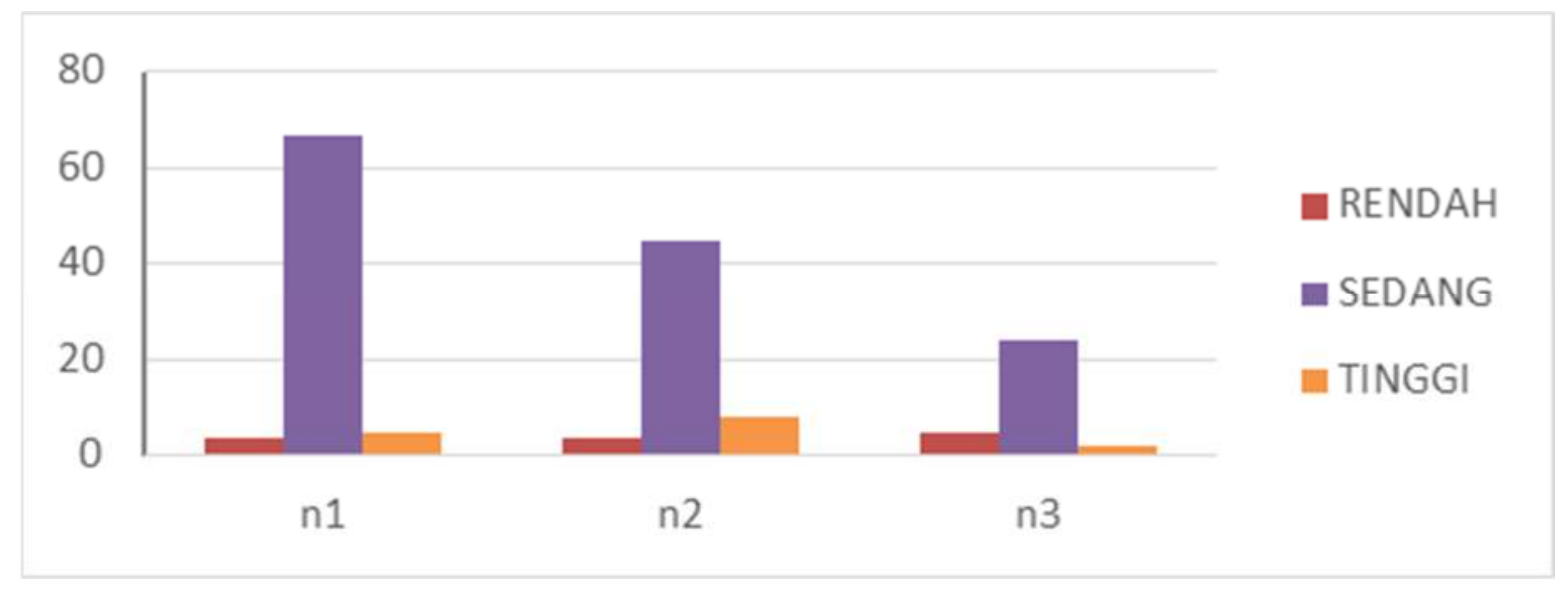

Terlihat dari tiap kelompok responden (n1, n2, dan $n 3$ ) didominasi oleh mereka dengan tingkat spiritual yang sedang atau menengah. Perlu dipahami bahwa spiritualitas pada diri tiap manusia berbeda-beda tingkatannya dan tidak selamanya seorang manusia akan selalu berada pada tingkat spiritualitas yang baik. Perbedaan itu terjadi karena dipengaruhi oleh dua faktor utama yaitu hubungan seorang nasabah dengan Tuhannya dan hubungan seorang nasabah dengan orang lain. Hubungan dengan Tuhan terkait dengan tingkat religiusitas nasabah yang mencakup keyakinan, praktek peribadatan, dan tradisi-tradisi agama yang dianut. Hubungan dengan Tuhan adalah pusat spiritualitas. Spiritualitas yang baik ditentukan oleh kualitas keterhubungan seorang manusia dengan aspek-aspek tersebut terutama Tuhan.

Spiritualitas memang sesuatu yang subjektif dan untuk mencapai tingkat spiritualitas tinggi secara stabil memerlukan waktu lama. Hal ini ditegaskan oleh 'Abdul-Qādir bahwa ketika Allah mengirim Rūhal-Quds sebagai ciptaannya yang paling sempurna ke alam yang paling rendah didasarkan atas alasan. alasan untuk mendidik. Rūh al Quds diharapkan mencari jalan kembali kepada kebenaran menuju tingkat Maha kuasa dengan cara mencari kedekatan dan keakraban sebelumnya dengan Allah. 
Kesimpulannya, musibah adalah cara Allah untuk mendidik manusia menuju tingkat spiritual yang lebih baik.

\section{PENUTUP}

Didasarkan pada masalah penelitian, tinjauan studi terdahulu, metode, dan hasil penelitian, maka studi ini menyimpulkan bahwa aspek demografi seperti jenis kelamin, tingkat pendidikan, dan pendapatan tidak memiliki asosiasi yang nyata dengan jenis bank yang dipilih masyarakat Indonesia. Hanya agama dan tingkat spriritual yang memiliki asosiasi yang signifikan atau nyata dengan jenis bank yang dipilih masyarakat di Indonesia. Studi ini membuktikan bahwa responden yang beragama Islam cenderung akan memilih bank syariah daripada bank konvensional, begitu pula dengan responden yang memiliki tingkat spiritual dengan kategori tinggi, mereka akan cenderung menjatuhkan pilihannya ke bank syariah.

\section{DAFTAR PUSTAKA}

Ajmi, J. H., Hussain, A., \& Al Saleh, N. (2009). Clients of Conventional and Islamic Banks in Bahrain: How They Choose which Bank to Patoiniz. International Journal of Social Economics, 1086-1112.

Balnkson, C, J. Cheng, and N.Spears. "Determinants of banks selection in USA, Taiwan and Ghana". International Journal of Bank Marketing 25, no. 7 (2007): 469-89.

Bley, J. and K. Kuehn. "Conventional Versus Islamic Finance: Student Knowledge and Perception in the United Arab Emirates." International Journal of Islamic Financial Services 5, no. 4 (2004): 17-30.

Devlin, J, and P. Gerrard, "A Study of Customer Choice Criteria for Multiple Bank Users". Journal of Retailing and Customer Services 12, no. 4 (2005): 297-306.

Dusuki, A.W. "Understanding the Objectives of Islamic Banking: a Survey of Stakeholders' Perspectives". International Journal of Islamic and Middle Eastern Finance and Management 1, no. 2 (2008): 132-48. W. Mansour, et al, "Islamic Banking and Customers' Preferences: the Case of The UK," Qualitative Research in Financial Markets 2, no. 3 (2010): 185-199.

Hamid, A. and N. Nordin. "A Study on Islamic Banking Education and Strategy for The New Millennium-Malaysian Experience." International Journal of Islamic Financial Services 2, no. 4 (2001): 3-11.

Haque, A, et al,."Factor Influences Selection of Islamic Banking: A Study on Malaysian Customer Preferences". American Journal of Applied Sciences 6, no. 5 (2009): 922-928.

Isnowati, Sri. “Faktor-Faktor Penentu Tabungan di Indonesia," Jurnal Bisnis dan Ekonomi 12, no.1 (Maret 2005)

Khan M. S. N, et al, Banking Behavior of Islamic Bank Customers in Bangladesh". Journal of Islamic Economics, Banking and Finance (2008): 159- 194. 
Kotler, Philip. Kartajaya, Hermawan. dan Setiawan, Iwan. Marketing 3.0 (Jakarta: Erlangga, 2011), 129-131

Lateh, N, S. Ismail and N. M. Ariffin, "Customers' Perceptions on The Objectives, Characteristics And Selection Criteria of Islamic Bank in Thailand”. Gadjah Mada International Journal of Business 11, no. 2 (2009):167-189.

Mansour, W, et al. "Islamic Banking and Customers' Preferences: the Case of The UK". Qualitative Research in Financial Markets 2, no. 3 (2010): 185-199.

Metawa, S.A, and M. Almossawi. "Banking Behavior of Islamic Bank Customers: Perspectives and Implications". International Journal of Bank Marketing 16, no. 7 (2006): 299-313.

Metwally, M. "Attitudes of Muslims towards Islamic Banks in a Dual-Banking System." American Journal of Islamic Finance 6, no. 1 (1996): 11-17.

N, Ahmad and S. Haron, "Perceptions of Malaysian Corporate Customers towards Islamic Banking Products and Services," International Journal of Islamic Financial Services 3, no. 1 (2002): 13-29.

Okumus , H. "Interest-Free Banking in Turkey: A Study of Customer Satisfaction and Bank Selection Criteria." Journal of Economic Cooperation 26, no. 4 (2005): 5186.

Schiffmanand, Leon G. Leslie Lazar Kanuk. Consumer Behavior. New Jersey: Pearson Prentice Hall, 2007).

Wan Ahmed, dkk, "Religiosity and Banking Selection Criteria among Malayas in Lembah Klang." Shariah Journal 16, no. 2 (2008): 279-304.

Zainuddin, Y, N. Jahyd, and T. Ramayah. "Perception of Islamic Banking: Does it Differ among Users and Non Users". Jurnal Manajemen and Bisnis 6, no. 3 (2004): 221232. 